\title{
Editorial: The Crisis of Democracy
}

\author{
Arthur Muliro ${ }^{1}$
}

Published online: 23 July 2018

(c) Society for International Development 2018

A cursory search of the title of this editorial on Google turned up well over 140,000,000 results in an astonishing $0.59 \mathrm{~s}$. Of the approximately 140 million results on the 'crisis of democracy', just under 40 million entries were one year old or less. A search for another common contemporary theme rife in the discussions of many intellectual elites 'Fixing Inequality' only turned up 5,230,000 results in $0.52 \mathrm{~s}$. What can we conclude from this rather unscientific experiment?

It is obvious that there is a lot of ink that is being spilled as to the crisis that democracy is in today. Recent events have obviously raised warning flags about the peril that the democratic enterprise finds itself in and much has been opined as to 'why now' and the imminent risks that the world faces should liberal democracy be overrun by illiberal variants of the same, opening the floodgates as it were for authoritarian regimes. Without succumbing to hyperbole and excessive dramatization of what is going on now, there is some form of regression currently unfolding around the world. In a recent article, The Economist magazine commented as follows:

The world has grown far more democratic since the second world war. In 1941 there were only a dozen democracies; by 2000 only eight states had never held a serious election. But since the financial crisis of 2007-08, democracy has regressed... In 2017, for the 12th consecutive year, countries that suffered democratic setbacks outnumbered those that registered gains. According to the Democracy Index from

Arthur Muliro

amuliro@sidint.org

Society for International Development (SID), Rome, Italy
The Economist Intelligence Unit, a sister company of The Economist, 89 countries regressed in 2017; only 27 improved. The latest "Transformation Index" from the Bertelsmann Foundation, another thinktank, which looks at emerging economies, finds that the "quality of democracy...has fallen to its lowest level in 12 years." What these indices measure is not simply democracy (i.e., rule by the people), but liberal democracy (i.e., with a freely elected government that also respects individual and minority rights, the rule of law and independent institutions). ${ }^{1}$

Perhaps the big question that we need to confront now is to try and understand to what extent the observed regressive trend is a blip on the screen as opposed to it being a permanent structural shift in the way we have approached and understood democracy hitherto. In this journal issue, the various authors provide us with insights that can help us find an answer to this dilemma. For the upfront section, two observers of democracy, the distinguished scholar, Prof. Jennifer Welsh and the award-winning journalist Roberto Savio (who has had a front row seat at some of the most dramatic events of the last 50 years) provide us with their views on the state of democracy. Their overwhelming message is that there is much to be worried about and that we should not assume that things will simply revert to normal after what we might consider a brief (however, we might choose to define this) moment of disruption.

In the Thematic Section, we have diverse viewpoints from around the world. Franck Amalric, in his article, challenges the notion that economics and finance are

\footnotetext{
1 After decades of triumph, democracy is losing ground, (14 June 2018) The Economist. Retrieved from: https://www.economist.com/ international/2018/06/14/after-decades-of-triumph-democracy-is-los ing-ground.
} 
superior to other areas of human enterprise and faults the exalted status that they have been accorded for the current demise of trust in the democratic model and for fuelling the populist backlash that we must now contend with in the West, but not only. Carmina Yu Untalan takes us on a journey to the Philippines to try and understand the Duterte phenomenon and how this came to be, and more in particular, how much of the population are cheering the demolition of a system that guarantees their rights with their approval of the cavalier and often extra-judicial methods favoured by the Filipino president. The sad case of Venezuela's decline has been documented severally and with much contestation, depending on the political sympathies of the authors. Maria Puerta Riera, gives us a contextual understanding of what this decline has meant and what the consequences of institutional failure are, and the havoc they are wreaking on the daily lives of many Venezuelans who have been reduced to penury and worse. In their article, Ibrahim Farah and Sekou Toure demystify the supposed benefits of regime change in Somalia and lament the top-down approach with which democracy is being engineered into the Somali nation. Their argument is that such approaches not only are destined to a miserable failure, but they are also delegitimizing democracy in the long run. There is a key and interesting point to be made about the observations from the Somali case.

For much of the past three decades, a critical element of western diplomacy included the export of democracy. Regime change was supposed to have removed brutal, obtuse dictators and ostensibly replaced them with more liberal, democratic and yes, western-friendly governments. It is difficult to see where there have been any positive outcomes from such adventures. The ruins in Baghdad, Tripoli and Kabul are perhaps testament to the folly that accompanied the democracy crusade. Why is it important to bring this up here and now?

These events - and others-have played a critical role in the rise of populist movements that were less wedded to the notions of global grandeur that have been hallmarks within the policy corridors of western governments in recent years. The same thinkers whose flawed ideas resulted in the adventures of the late 1990s and the turn of the century are the same ones who today decry the crisis within liberal democracy. In a recent trenchant article, John Gray wrote:

The recent age of progress, whose passing liberals mourn, included unending war in Afghanistan, a European migrant crisis rendered intractable by anarchy in countries where Western intervention destroyed the state, a global financial crash and decades of stagnant or falling living standards for swathes of the population in many Western countries. Unfolding disasters such as the American opioid epidemic and attendant fall in life expectancy have their roots in the corporate predation and ravaging of communities that occurred under the regime over which liberals of one kind or another presided. But they can comprehend the disorder of the present only on the basis that they had no part in creating it. They continue to believe their hegemony was a reflection of their superior rationality. The current hiatus can only be a passing spasm of unreason and the prelude to a state of normalcy returning in which they are once again in charge.

The denial by liberals of any responsibility for the conditions that have fuelled rising anti-liberal movements is the cardinal fact of contemporary politics. What this denial presages is not any higher phase of history - a revamped liberal order, or some purer version of socialism-but a new authoritarian era. The world has reverted to a condition not dissimilar to that which prevailed towards the end of the 19th century. Harnessing unchanging human needs for security and identity, great powers are deploying new technologies in the pursuit of primacy and survival. $^{2}$

So where does this leave us now? There will need to be some humility in rethinking our approaches to democracy, even as we work to reaffirm some of the principles that have been its central tenets-citizen equality, belief in constitutional authority, checks and balances to power and systems to uphold the rights of individuals and minorities within them. The key thrust of the populist leaders gripe with liberal democracies is that they are constrained by laws (and hence clamouring for the dismantling of constitutional checks and balances) and that there are significant 'others' who pose a threat to them and their ilk (hence their focus on immigrant populations, minorities within their countries and migration overall). The messaging around these key principles is complicated and likely to be messy. Populist leaders have generally a disdain for facts and contempt for expertise. A critical result of this is that key policy processes are no longer being driven by solid data or facts, but more by emotional whims that characterize the day. For instance, policies around immigration do not consider the actual numbers of migrants but are built more around a message of 'stemming an invasion'. Europe, for instance, is today totally tied up in knots over a migrant crisis, with politicians losing no opportunity to warn the public of the need to act with haste so as to forestall the invasion of 'hordes' on the shores of North Africa awaiting to cross the Mediterranean and into

\footnotetext{
${ }^{2}$ Gray, John, How we entered the age of the strongman, (23 May 2018) New Statesman, Retrieved from: https://www.newstatesman. com/world/2018/05/how-we-entered-age-strongman.
} 
Europe. A cursory glance at the data shows that apart from a spike in numbers in 2015 when some 1 million migrants were admitted into Europe (the bulk ostensibly refugees from the Syrian crisis), the numbers have been steadily declining. In 2016, there were some 374,000 arrivals into the EU, in 2017, just under 185,000 and at the time of writing (June 2018), just over 50,000 arrivals had been recorded. ${ }^{3}$ One could argue, on the face of the facts, that there really isn't a migration crisis that is of existential threat to Europe. Rather, what we have is a political crisis that has taken the migration issue hostage.

Unfortunately, for the democratic process, this tendency to play loose and fast with facts will have dire consequences. Such an approach not only ensures that trust within society is further diminished, but it also polarizes the polity and permanently weaponizes policy debates, obfuscating facts and seeking to discredit (if not annihilate) those whom might have ideas or positions opposite to those of the leadership. As these processes degenerate into culture wars, we are forced into tribe-like formations which are driven more by loyalty to individual leaders than to the values and ideals that constitutions might espouse.

So, what then can we expect of democracy in the coming years? On the one hand, we might be inclined to think of the current crisis as a temporary glitch, one that will eventually self-correct as the checks and balances of democracy's institutions kick in and take over. This is a distinct possibility and if this should happen, then perhaps there will be not much more to worry about other than sigh in relief at the passage of a dark set of clouds. On the other hand, there is a distinct possibility that the current pressures on democracy will overwhelm it and yield to something that is less salubrious for society as a whole. This fact alone should spur us to rethink what needs to be done in order to ensure that democracy remains viable and relevant, not just for the present, but for the future. In a recent article reviewing David Runciman's book 'How Democracy Dies', Murtaza Hussain wrote:

Democracy is eroding and may no longer be a plausible means of governance. Technological change, decaying institutions, and populist demagoguery may well make genuine democracy effectively impossible, validating [John] Adams's prediction that a democratic system could never really endure... Among the threats we face are global problems like climate change and inequality, which our dysfunctional democratic systems have proven incapable of responding to... in the West, democracy is more likely to simply fracture and fizzle out over time. As our political institutions become less and less able to

\footnotetext{
3 European Commission Press Office. https://twitter.com/PrensaCE/ status/1010815746958557184.
}

deliver meaningful results and the speed of technological change continues to warp and remake society, democracy could effectively die while continuing to appear alive. ${ }^{4}$

It is perhaps too soon to write the final epitaph on democracy. Certainly, the trends that are unfolding are worrying, but this fact alone should be a wake-up call for us to try and diagnose accurately the reasons for its current failings and to seek remedies that can respond to present and emergent challenges. In this regard, it is critical to understand the linkages between the growing inequalities, hoarding of power by elites and the current afflictions of the democratic process. In this respect, Chris Hedges article 'The Deadly Rule of the Oligarchs" 5 offers a useful primer for those who might be seeking to understand more succinctly these linkages.

Ultimately, reconfiguring democracy to make it functional for our times requires that we rethink our societies and rediscover the communal nature of the exercise-one which calls for the complete engagement of our minds and energies to remake spaces in we can celebrate what is important to us, but also facilitate meaningful exchanges of ideas that contribute to learning and innovation. In many respects, this will require a conscious effort to repudiate the individualism and isolationist tendencies that prevail today. In short, we need to rededicate ourselves to a common project. As Michael Behrent wrote in his review of Marcel Gauchet's 'The Advent of Democracy':

The pursuit of individual autonomy as the ultimate justification of human life and social existence accounts for the growing distaste for politics and the waning sense of participating in a national history. ${ }^{6}$

This journal issue has attempted to offer some insights into ideas around how individual thinkers are conceptualizing and responding to the challenges that democracy is facing around the world. Whilst there are no magic solutions that are offered, they do give us significant food for thought. If today the crisis of democracy is receiving attention, it is because this crisis has been spreading within western institutions that were supposed to have been paragons of the democratic ideal and from which many other (nonwestern) countries were supposed to learn. The reality is that the liberal democratic model which has been the

\footnotetext{
${ }^{4}$ Hussain, Murtaza, Democracy Dies in the Blinding Light of the Day (4 July 2018) The Intercept. Retrieved from: https://theintercept. com/2018/07/04/how-democracy-ends-david-runciman-review/.

5 Hedges, Chris, The Deadly Rule of the Oligarchs (11 February 2018), Truth Dig. Retrieved from: https://www.truthdig.com/articles/ deadly-rule-oligarchs.

${ }^{6}$ Behrent, Michael, The Age of Emancipation (Winter 2018), Dissent Magazine. Retrieved from: https://www.dissentmagazine.org/article/ age-of-emancipation-marcel-gauchet-democracy-review.
} 
primary vehicle for democratization has not performed brilliantly elsewhere. There will need to be-as earlier mentioned - a greater degree of humility as we think through how to remake the institutions of democracy more relevant to the lives and aspirations of the majority. We may therefore take heed of the findings of Papoulidis and Cooley who reinforce the value of social capital in helping renew and legitimize institutions. Much as their work was focused on fragile states, this finding could very well apply to all states. Furthermore, it is likely that the future as it unfolds will probably not resemble anything that we are used to at present. If the reconceptualization of democracy has to work, it cannot be based on a one-size-fits-all template: each society will most probably have to find what works for it and adapt accordingly. There might be similarities, but most likely there will be significant dissimilarities-a likelihood which is bound to create significant discomfort in a world that is homogenizing just about all that it can. As Magode Ikuya in his article tells us, the prevailing ideologies of the day will have to be derived from thought processes within the masses grappling with their existing problems. In other words, imported models and short cuts are not likely to lead to democratization but more disempowerment of the people.

In the final analysis, the survival of democracy will not be the outcome of some benevolent action by some dark forces but rather the fruit of a committed effort to engage and rethink what sort of society we would like to jointly work towards. It will require us to move well beyond the comfort zones that many of us might have adapted to and begin to appreciate the reality that is unfolding in front of our eyes. Whilst many of us might imagine we are insulated from the ravages of daily conflict, displacement, climate change and dysfunctional institutions, we could be in for rude shocks when this veneer of comfort and wellbeing evaporates. In order to understand the task ahead of us, I find no better alternative than to quote from Behrent once more:

First, we best understand democracy—and grasp its most vital impulses-when we understand it as a struggle, as a centuries' long process whereby human beings reclaim powers they had once attributed to the gods. The tragedy of neoliberalism is that it has made us all Americans-in Gauchet's admittedly problematic sense of a people to whom democracy came by virgin birth, with no pitched battle against a hierarchical or feudal past. Second, democracy is hard. Not in the conventional sense that citizenship requires commitment and effort. Democracy is demanding because it requires us to dispense with heteronomy, to which humans have often turned to solve many of their problems-including those arising from democracy itself. Can we live as autonomous beings, while recognizing the precariousness of this endeavor? Democracy's fate, Gauchet teaches us, may hinge upon it.

If we can imagine a different future, one in which our societies are more economically just, more sustainable and less aggressive, then perhaps we can lift ourselves out of the current crisis. There are alternatives to the present situation-they just require a lot of hard work to make them viable. 